\title{
Study of SME Financing based Supply Chain Finance*
}

\author{
ZHAO Zhiqiang \\ Department of Economics and Management Ankang University, Ankang, Shaanxi Province, CHINA \\ zhiqiangzhao99@163.com
}

\begin{abstract}
How to solve the SME (small and medium-sized enterprises) financing difficulty domestic scholars has always been the hot topic to study, the enterprise net cash flow condition will determine the fate of the business, supply chain financing provides new ideas for to solve this problem. This paper researched the concept and the current situation of supply chain finance, systematically planning the supply chain financing, puts forward some constructive suggestions for solving financing difficulty.
\end{abstract}

Index Terms - Supply chain finance, financing, credit

\section{What Is the Supply Chain Finance}

Supply chain finance is the bank will supply chain relevant enterprises as a whole object, through effective integration the supply chain members information flow, capital flow and logistics. According to the enterprise receivables, inventory, prepaid etc liquid assets to design the program. Use various financial products for all enterprises in the supply chain, especially the upstream and downstream to provide financing services to SMEs, allows the supply chain relevant SMEs get financing support, so as to solve the supply chain problem of unbalanced distribution of funds. Enhance the competitiveness of the entire supply chain. Supply chain is becoming the mainstream of the international industrial organization model, which requires the core enterprise has higher supply chain management level. Not only to better coordinate the supply chain section between the upstream and downstream businesses good relationship, while as much as possible use including logistics companies, financial institutions and electronic trading networks such exterior institutional support type service.

Supply chain finance is the result of combining logistics and finance, which includes financial services function supply chain services, supply chain financial services is no longer one-sided emphasis on the fiduciary entity's financial characteristics and industry position, and no longer simply based on the isolation of a fiduciary of the main evaluation to make credit decisions, but to really pay attention to and trade with their real background. The greatest feature of supply chain finance supply chain is looking for a large core business, which is the starting point for the entire supply chain to provide financial support.

\section{Financing Status of SMEs Based on Supply Chain Financing}

At present domestic many banks begin to devoted to providing supply chain management services for enterprise, but domestic enterprise supply chain management consciousness widespread weak, whole supply chain have the potential risk, the enterprise information technology lag, the core enterprise positive is not high. Many SMEs lack of awareness of supply chain financing, used to get from the common form of long-term bank loans, don't know how to effectively use the financial resources, the financing combined with upstream and downstream firms, arrange financing at the supply chain characteristics and their situation, thus losing many financing opportunities, reduced the enterprise international market reaction ability and competition ability.

China's SMEs supply chain financing have obvious structural and institutional constraints. Domestic supply chain financing relatively concentrated on automobiles, steel few limited industry, most other industries supply chain financing develop relatively slowly. The key factor restricting the domestic commercial banks development is lagging seriously behind of new business development in the supply chain financing. Meanwhile, the lack of supply and demand sides to take concerted action in order to optimize the internal supply chain financing incentives.

There are no relevant legal terms and industry guidance document can basised. There has big financial risk and legal risk which has been formed in the supply chain financing. Overdue receivables high and the complex debt relation between enterprises, make commercial banks faced huge risk in the supply chain financing business. According to relevant authority statistics and analysis, in developed market economy countries, an enterprise of overdue receivables amount between accounts for total trade $0.25 \%-0.5 \%$, and in CHINA it by over $5 \%$.

Partial enterprise credit notion weak, debt consciousness strong and debt-repaying consciousness inadequate. In the supply chain financing, unscrupulous obtain the bank loans and used for other purposes, resulting in recovery of bank funds difficult. Some loan enterprise forged contracts obtaining credit, accounts receivable payer refused to pay, Makes accounts receivable pledge loan implied greater risk. Supply chain financing related to different subjects and behavior, requirements of various behaviors of legal rights and responsibility have corresponding legal definition, but the legislation of our country is slower than the service development, legal lag also resulted in credit system has not been effectively building.

Lack of a sound credit system, Lead to supply chain financing both sides appear interests deviation. between the members of the supply chain enterprises, between the enterprises and banks relative lack of reliable credit guarantees. Both sides of supply chain financing, often financing from their own interests: financial institutions to guard against financial

\footnotetext{
* Scientific Research Program Funded by Shaanxi Provincial Education Department (Program No.12JK0062); AnKang University (Program No. AYQDRW201204)
} 
risks, consideration is safety, liquidity, profitability unity, so the process of financing, mortgage, or by way of security, financing, corporate credit status have more stringent requirements; but finance companies consider the links between the needs, costs and benefits, when the cash flow difficulties only considering to obtain financing, pursuit of the supply chain operational efficiency and capital utilization. Lead to supply chain financing deviation of interest both directly restricts the healthy development of supply chain financing.

\section{Financing Mode Analysis of SMEs based on Supply Chain Financing}

Supply chain finance means a bank from the angle of whole industry chain carry out integrated credit. And make single enterprise's risk management change into industrial chain risk management. Supply chain finance has the following kinds of basic business model:

\section{A. Accounts Receivable Financing Mode}

Accounts receivable financing mode refers to the SMEs to supply chain core big enterprise accounts receivable documents vouchers as to commercial banks pledged collateral, application deadline for not more than accounts receivable aging short-term loans from banks, for the SMEs in supply chain upstream provide financing ways. In the financing model, the creditor enterprises, SMEs, corporate debt, the core of large enterprises and banks to be involved, and debt business in the whole play the role of counter-guarantee, once the financing business problems, companies will also assume debt compensate banks for the losses.

\section{B. Confirming Warehouse Financing Mode}

Confirming warehouse business refers to the industrial chain of big enterprises as the core producer, under the precondition of commitment by the buyback ,financing enterprise applies to the bank, for bank designated by the seller, the established for impawn warehouse, get bank loans, and by the bank to control its delivery conditions of power for financing services. Confirming warehouse business in addition to need in supply chain of manufacturers, downstream ethnics-people dealer, financing the participation of enterprise and bank outside, still need to logistics enterprise, warehousing and the involvement of regulators, responsible for the collateral evaluation and supervision pledged product.

\section{Finance-transportation Financing Mode}

Inventory financing is the enterprise to inventory as a pledge to financial institutions for financing business behavior. When the enterprise is during in pay cash to sell inventory of business process, enterprise can use the inventory finacing mode. The so-called finance-transportation refers to the third party logistics enterprise to provide a integrated innovation service of financial and logistics, it can not only provide high quality, high value-added logistics and processing services, also can provide the directly or indirectly financial services to customers, in order to improve the overall performance of the supply chain and customer management and capital operation efficiency.

\section{Promoting the Development of SME Supply Chain Financing Countermeasures}

Expand SME supply chain financing services, important is to strengthen the supply chain financing business risk prevention, innovation supply chain financing subject, in the service mode seek new breakthrough, and supply chain and industry chain and service supporting the rapid development of small and medium-sized enterprises, is the dominant force of domestic supply chain development. But their own strength remains to be strengthened, and the lack of the strength to the world and resist the ability of the risk, urgent need the government policy and financial support.

\section{A. Establish Public Financial Service Chain Platform As Quickly}

As quickly established by the government authorities and industry associations-led integrated financial services network platform, use this platform can realize supply chain finance business online optimization, through this platform's channels and information, the bank can provide comprehensive services including credit, settlement, financial and capital management. Replace part of that person's role in enterprise financial people.

\section{B. Improve Internal Operational Efficiency Of Capital, Bank and Enterprise Build a Standardized Supply Chain Management System}

SME supply chain financing business expand, in addition to banks and other institutions to design more comprehensive supply chain financing and technology to provide more effective supply chain management services, but also need enterprises actively participate to build the co-constructing and standardized and institutionalized supply chain management system, commercial banks with the core enterprise to establish comprehensive strategic partnership.

\section{Build Data Shared Information Supply Chain Financing Service Platform, Breakthrough Chain Financing Technology Bottleneck}

Supply chain efficiency mainly depends on the information management technology level, through the sharing information, make supply chain enterprise make timely or adjust the production and business operation strategies, achieve the enterprise of chain existing resources optimization allocation of efficient conformity, and realize its value maximization. Build data shared information supply chain financing service platform need logistics, bank, enterprise various efforts, supply chain financing service platform not only for commercial banks, enterprises and supply chain information transfer and sharing platform, but also to utilize the platform-related credit rating business operations, information search and other functions.

\section{Establish and Perfect The SME Credit Evaluation System}

Market economy is an credit economy, based on a sound credit system and credit-based relationship. Although the supply chain financing can effectively avoid the risk of individual enterprises, but still can not eliminate the credit risk, establish a complete credit system is the protection of supply chain financing. Previous domestic commercial banks to all 
enterprises credit rating use uniform standards, SME restricted by the scale of strength, meet the lending standards are minimal, which requires commercial banks to adjust credit standards for SMEs, research to develop a consistent characteristics of SMEs credit rating, the rating method, while reengineering the SME business process and establish a sound credit rating system consistent with the SMEs and loan management mode.

\section{E. Develop the Third Party Logistics For Supply Chain Financing Service To Circumvent Credit Risk}

Commercial banks supply chain financing services, large extent rely on the support of third party logistics enterprise, the third party logistics enterprise offer is a financial and logistics integrated type innovation service. To promote the supply chain with larger role in promoting financing, logistics enterprises in over the pledge of movables, worth preserving assets supervision outside, still will provide for bank credit guarantee efficiency increase of value-added services, reduce and transferring bank loan risk, set for the supply chain enterprise risk firewall, provide more convenient financing opportunities. Therefore, supply chain financing service in the implementation of largely also rely on logistics mature development, rely on logistics enterprise the credit strength, starting from logistics industry evade credit risk.

\section{F. Extended Supply Chain Financing Areas, to promote Development of the Supply Chain Indirect Financing to Direct Financing.}

China's current supply chain financing schemes introduced various is commercial bank as intermediary agencies mainly indirect financing ways, supply chain direct financing hasn't started. To direct financing by indirect financing transformation is the inevitable trend of the supply chain financing, only vigorously develop the supply chain direct financing under the capital market, plagued many years of china smes' financing difficult problem was likely to get changed fundamentally, the supply chain financing to have qualitative leap.

\section{References}

[1] Wang lei. Based on supply chain smes' financing explore. Productivity Research. 2010,10

[2] ZhuWenFeng, HanKeYong. Supply chain financing --the new credit mode to solve the difficulty in financing smes. Productivity Research. 2010,07

[3] Shenzhen development bank, China Europe international business school "supply chain finance" group. The supply chain financial. Shanghai far east press. 2009

[4] LiQin, HanKai. Supply chain financing present situation and problems :93 enterprise samples. Reform . 2009,6

[5] WuQun. SME private enterprises' financing system innovation under the new situation. Modern Economic Research. 2008,11 